\title{
Developing a Framework for Understanding Lecturer-Student Interaction in English-Medium Undergraduate Lectures in Sri Lanka: First Step Towards Dialogic Teaching
}

\author{
A. M. M. Navaz ${ }^{1}$ \\ ${ }^{1}$ Department of English Language Teaching, South Eastern University of Sri Lanka, Oluvil, Sri Lanka \\ Correspondence: A. M. M. Navaz, Department of English Language Teaching, South Eastern University of Sri \\ Lanka, Oluvil, Sri Lanka. E-mail: navazamm@seu.ac.lk
}

Received: September 20, 2020

Accepted: October 20, 2020

Online Published: October 28, 2020

doi:10.5539/ijel.v10n6p395

URL: https://doi.org/10.5539/ijel.v10n6p395

\begin{abstract}
This study focuses on developing a framework to identify dialogic interaction in English-medium science lectures in a small faculty of a Sri Lankan university. In Sri Lanka, English-medium instruction was introduced with an objective of developing language proficiency of students along with the content delivery. It is asserted that teacher-student interaction in ESL content classes would help develop language proficiency of students. However, generally, lectures in English-medium undergraduate courses in Sri Lanka tend to be monologic, leaving the language development a question. The lecture delivery style, along with other reasons, affects students' language development in English-medium classes. Although increased dialogic interaction could help change this situation, few studies have examined the occurrence of dialogic interaction in tertiary-level ESL science classes. The main objective of this study is to develop a framework by analysing the lectures given at the faculty in a method that contextually suits the lecture delivery style in the Asian countries. Data were collected from transcribed recordings of 12 hours of lectures, involving four lecturers. The interactional episodes in the lectures were the basis of developing the analytical framework, which refines and extends the MICASE corpus interactivity rating in a contextually-focused way, was especially designed to categorise the lecture discourse along a monologic-interactive/dialogic continuum. This paper also suggests how this framework could be adopted to analyse the lecture deliveries from a practitioner's point of view. Within the scope of this paper it is explained how this framework was designed focusing attention to interactional episodes. It can be envisaged that the proposed framework can make a concrete contribution to teaching and learning in higher education, mainly to the concept of developing language through dialogic lecture delivery at tertiary level ESL content classes.
\end{abstract}

Keywords: dialogic interaction, monologic lectures, lecturer-student interaction, lecture discourse, Sri Lanka

\section{Introduction}

This study, which was undertaken in the context of English-medium science lectures at a small faculty in a Sri Lankan university (called Faculty of Science, FS) where English is spoken as a second language (ESL), investigates teacher-student interaction from a dialogic point of view. It analyses the lecture discourse collected in order to present an analytical framework for identifying the occurrence of dialogic interaction in lectures.

Classroom interaction received considerable attention in the recent past (Morell, 2004; Pedrosa de Jesus \& da Silva Lopes, 2009, 2011; Prakash, 2010) because it is believed that classroom discourse of dialogic nature could help the knowledge development of the students, while it provides opportunities for language development. Traditionally, lecture discourse is identified as monologic (the lecture is delivered without any interaction with students) or interactive (where lecturer and students involve in a sequence of questions and answers). Hence, this interactive lecture could be dialogic or authoritative (the latter is also known as non-dialogic); these two terms were introduced based on the work of Scott, Mortimer and Aguiar (2006) and have gained wider popularity (Matusov, 2009; Juuti et al., 2019). Scott et al. (2006) introduced four categories of classroom discourse, as explained later. Two of those categories are (1) interactive-dialogic: this means teacher and students explore ideas together and therefore interactive, and also generate new meaning, making the discourse dialogic. Dialogic talk acknowledges multiple voices in the classroom (Matusov, 2009) as teachers ask students their views regarding the topic or phenomenon under discussion (Scott et al., 2006). Dialogic interaction, at this point, can 
be defined simply as a mutual dialogue that takes place between a teacher and students. In other words, it is an interaction in which both the teacher and students mutually contribute to the discourse with a view to exploring or developing a concept in a lesson.

Scot et al.'s second category is (2) interactive-authoritative (teacher leads students to a point desired by him or her through a sequence of questions and answers). In this category, though there is interaction between the teacher and students, this interaction is made of simple question and answer sequences such as the one given below from the collected FS discourse. These exchanges are also known as recitation scripts (Tharp \& Gallimore, 1988) in which one-to-one question and answer sequences exist.

\section{E.g., Lecturer: What is PCR?}

\section{Student: Polymerase Chain Reaction}

Lecturer: Yes, correct. (From FS discourse, Biotechnology subject)

In this exchange, the lecturer does not use the students' views in construction of knowledge and therefore, it is considered interactive - non dialogic.

Dialogic interaction enables students in helping the meaning making process (Mortimer \& Scott, 2003) and it helps in thinking and understanding. Barnes (2008) explains that the exploratory talk, which is similar to dialogic talk, is important in learning because it provides a ready tool for trying out different ways of thinking and understanding. Dialogism, which has its origins in the conceptual work of Bakhtin (1981), was further developed as a dialogic teaching approach by Alexander (2006), while the dialogic value of interactional episodes has been identified by the work of Mortimer and Scott (2003) in secondary level science classes.

In Sri Lanka, just like other Asian countries, lecture deliveries are considered to be mostly monologic. The majority of the lecture deliveries do not favour a participatory learning which allows the students to be active in the learning process. Lecturers have been exposed to participatory or student-centered learning during their staff induction training programmes, but the outcomes of such trainings are not visible. In Sri Lankan classrooms, there are several reasons for students' reticence that include cultural barrier and an alleged fear of being punished by lecturers if they tried to interact with them. The researcher has discussed these reasons in another paper (Navaz, 2013). Therefore, it is imperative for the lecturers to adopt a suitable lecture delivery style where opportunities are available for students to contribute to the lesson by active participation. However, to my knowledge, no systematic studies so far in Sri Lanka have unearthed the lecture delivery style in Sri Lankan tertiary sector. Hence, this study will attempt to take the first step towards developing this favourable lecture delivery style in Sri Lankan tertiary classrooms.

\subsection{Objective}

Objective of this study is to design a framework to understand the occurrence of dialogic interaction in the FS lectures.

At the backdrop of the fact that the studies that investigate the interaction either in Asia or Sri Lanka are very limited, this study will design a framework to investigate the occurrence of dialogic interaction which involves students in the centre of the learning process. Such a study will have two advantages; one is to understand the present situation of lecture delivery and the other one is to inform the lecturers the desirable lecture delivery style that they could adopt in delivering lectures for the benefits of understanding the content and developing the language of their students. Hence, this study will have the following research questions.

1) How can an analytical framework be developed for measuring lecturer-student interaction in content based undergraduate lectures?

2) How can the framework be used from a practitioner's perspective?

\section{Literature Review}

\subsection{Importance of Interaction}

Classroom interaction is considered to be important for learning, so any attempt to improve teaching and learning should consider classroom interaction as a potential area for development (Walsh, 2011). This claim is made based on the assertion that language is the medium of acquiring new knowledge and also, in language classes, language is used as both the medium as well as the goal of the study (ibid). Similarly, oral interaction that occurs between teachers and students and among students is deemed to be important in creating a suitable learning environment and for learners' development (Hall \& Verplaetse, 2000). Interaction in content classes may help students' academic L2 (Second Language) competency (Verplaetse, 2000) by giving them an 
opportunity to practise the language to reach fluency and hear the academic talk and later appropriate it. Hence, it is generally believed that through interaction, not only students' academic communication skills, but also their second language develops (Gibbons, 2003; Gibbons, 2015; Gupta \& Lee, 2015; Haneda, 2005; Haneda \& Wells, 2010).

Dialogic interaction includes mutual consideration of different and even diverging views (Lehesvouri et al., 2017; Taylor \& Lelliott, 2015). The importance of dialogic interaction in learning has been emphasised in sociocultural perspectives on learning in both L1 (English is used as the first language) and L2 (English as a Second Language) contexts. Alexander (2006) regards dialogic teaching as "[it] harnesses the power of talk to engage children, stimulate and extend their thinking, and advance their learning and understanding" (p. 37). Further, dialogic talk promotes communication through authentic exchange during which the teacher helps students share and build meaning (Hiltunen et al., 2020; Molinari \& Mameli, 2010). Similarly, Mercer, Dawes and Staarman (2009) argue that through dialogic teaching the classroom communication should focus on organizing students' educational experience to the progressive development of their understanding. Sociocultural theory, built on the work of Vygotsky (1978), elaborates that the role of language and interaction between the teacher and the learners are important for the L1 as well as L2 learners (Mercer, 2001). Following the path of Vygotsky's sociocultural theory, social constructivists (e.g., Mercer, 1995; Staarman \& Mercer, 2010) argue that teacher-led discussions are important for learning in the classroom. In this kind of learning, the teacher has an important role as he or she is the one who should exploit students' present understanding and "make explicit their thoughts, reasons and knowledge" through appropriate use of questions (Rojas-Drummond \& Mercer, 2003, p. 101). The argument is that the classroom talk should be dialogic with mutual contributions from both the students and the teacher for developing the discourse, which in turn can be a good platform for content and language learning (Swain \& Lapkin, 1998).

\subsection{Dialogic Teaching}

Alexander's dialogic teaching has five essential features: (1) collective (teacher and learners address learning tasks together); (2) reciprocal (teacher and learners listen to each other, share ideas and consider alternative view points); (3) supportive (learners articulate their ideas freely, without fear of embarrassment over 'wrong' answers, and help each other reach common understanding); (4) cumulative (teachers and learners build on their own and each other's ideas and chain them into coherent lines of thinking and enquiry); and (5) purposeful (teachers plan and steer classroom talk with specific educational goals in view).

Different researchers have adopted different tools for measuring or identifying the occurrence of dialogic teaching in content classes, mainly in L1 classes. Sedova (2017) has presented five key indicators. They are (1) the expression of students' thoughts with argument and or reasoning; (2) a teacher's open question of high cognitive demand, mainly authentic questions. Students have to answer these questions using their cognitive skills but not from memorizing; (3) uptake which is a kind of follow-up, usually from student's answer teacher builds on the conversation; (4) the occurrence of student questions and (5) open discussion-a sequence of questions and answers that includes at least three participants. These indicators are similar to Alexander's principles of dialogic teaching, as given earlier.

Hennessy et al. (2016) invented a detailed system of codes to investigate the occurrence of dialogic teaching. This system is known as SEDA (Scheme for Educational Dialogue Analysis) '[It] is the result of a 3-year British Academy funded collaboration between two large teams in the UK and Mexico with extensive collective experience of researching dialogue across multiple contexts' (ibid, p. 17). This coding system consists of 33 Communicative Acts. The proponents claim that SEDA helps them determine this dialogicality, as well as the specific nature and progress of any dialogue observed (Hennessy et al., 2016). The SEDA is divided into 8 clusters. They are: (1) Invite elaboration or reasoning (2) Make reasoning explicit (3) Build on ideas (4) Express or invite ideas (5) Positioning and coordination of ideas (6) Connect links to ideas (7) Guide direction of dialogue or activity (8) Reflect on dialogue or activity (Vrikki et al., 2019). These eight clusters are divided into 33 communicative acts.

The models proposed by Sedova et al. (2017) as well as Hennessy et al. (2016) build on the principles of dialogic teaching proposed by Alexander (2006). Hence, many of these studies arise from L1 content classes. In reality, the situation in L2 content classes is different as far as interactivity or dialogicality is concerned. In Sri Lankan tertiary level ESL content classes, there is lack of interaction and the main focus of lecture deliveries is content delivery through lecture talk. It is presumed that in lectures the available limited interactional exchanges focus on display type questions for which the lecturers do not expect answers. At this backdrop, in Sri Lanka, for enhancing more student participation in L2 content classes, student-centred teaching approach was proposed, 
mainly for the university teachers, but no visible impacts have been reported yet. In a previous study by the researcher (Navaz, 2014), it was found that despite the instruction on student-centred teaching, the lecturers and students had a wrong notion of the term student centred. For them it was a mere question and answer sequence, without considering the type of discourse developed.

In a country like Sri Lanka, the dialogic teaching could bring benefits to the students. If it is implemented properly, the outcome would be positive. However, to what extent the lecturers have the knowledge of the dialogic teaching is a question. Generally, the student population in tertiary level classes has mixed language skills. Lecturers, therefore, have to play the main role of initiating, developing and maintaining dialogic interactions. Further, it will be beneficial for any higher educational institute for having an understanding of the dialogic lecture delivery style. This understanding will help, mainly to orient the lecturers towards dialogic lecture deliveries, for its potential benefits for students' educational as well as language development in L2 contexts. Therefore, with the increased importance of dialogic interaction the need for understanding the occurrence of dialogic interaction arises, especially at tertiary level L2 lectures but the mechanisms to identify such interaction have not yet been developed to match the lecture deliveries in Asian countries. The MICASE corpus has already classified lectures into interactive and non-interactive categories (Simpson-Vlach \& Leicher, 2006), but the dialogicality of the lecture discourse is not taken into consideration.

In the absence of studies that classify lecture discourse in terms of its dialogic value in the L2 content lectures, developing a framework to identify the occurrence of dialogic interaction could bring benefits by way of diagnosing the existing lecture delivery for its dialogicality as well as promoting the teachers to orient the lecture delivery towards dialogic teaching. Hence, it is believed that this study would fill the gap by developing a framework for identifying the occurrence of dialogic interaction in tertiary level English-medium lecture discourse. In this study, there is a small corpus of FS lectures and hereinafter referred to as FS discourse. The measures used to collect the FS discourse are explained next.

\section{Methods}

This study was undertaken at a small faculty of a university in Sri Lanka, and the faculty is known as FS. In the faculty there are three departments: Biology, Mathematics and Physics. Two-degree programmes are offered: Bachelor in Biological Science and Bachelor in Mathematical Science. The medium of instruction is English.

The main data for the study come from the lecture discourse of around 12 hours of lectures delivered by four lecturers from these three departments. In selecting the lecturers, a purposive sampling method was used, as the lecturers who taught the second-year students only were considered for the study. Another consideration was the preference that was given to the senior lecturers. It was decided to consider the senior lecturers because it was assumed that more interaction could be found in senior lecturers' lecture delivery. Of the six senior lecturers who volunteered to participate in the study from those three departments, four lecturers were selected considering two criteria. One was the lecturers who conducted lectures for the second-year students. The other one was two of the four senior lecturers (herein after referred to as lecturers) should be teaching to the Biological Science students, while the other two to Mathematics students to make a representative sample. Two of them had PhDs (ML1 and BL1), while other two had MPhil degrees. All had followed their bachelor's and higher studies in English-medium and at the time of the interview they had several years of teaching experience in EMI (English-Medium Instruction) classes, as shown in Table 1 below.

Table 1 indicates the lecturer identification. $\mathrm{M}$ refers to Mathematics, $\mathrm{B}$ refers to Biology and $\mathrm{L}$ refers to lecturers. The gender was not considered as a criterion for the selection of the lecturers as it was not a factor for investigation within the scope of this study. However, out of the four selected lecturers, two happened to be females, which made a gender balance in the lecturer sample.

Table 1. Details of lecturers' sample

\begin{tabular}{lllll}
\hline Identification No & Subject & Department & Gender & Teaching Experience (Years) \\
\hline ML1 & Physics & Physics & Male & 10 \\
BL1 & Biotechnology & Biology & Female & 10 \\
ML2 & Applied Statistics & Mathematics & Male & 09 \\
BL2 & Animal Physiology & Biology & Female & 12 \\
\hline
\end{tabular}

\subsection{Collection of FS Discourse}

Lectures delivered by the lecturers were identified with the short form of the name of the subject. PH, BT, AS, 
and AP refer to Physics, Biotechnology, Applied Statistics and Animal Physiology in the order mentioned. Further a number was given to match the sequence of lectures recorded. For example, the third lecture in Biotechnology was identified as BT 3 and so on. However, this number refers to the observation and recording only but does not indicate the lecturers' lecture series order. The lectures were recorded using a pocket voice recorder which the lecturers carry during the lecture delivery and the researcher was also present in the class during the lecture delivery taking field notes. The lecturer was asked to go near the students as much as possible when interaction occurs between the lecturer and the students.

The lecture recordings were transcribed verbatim using Sound Scriber, a software produced by MICASE, downloaded from the MICASE webpage. Students were identified as for example MM1, BM1, MF1 or BF1. The first M or B refers to Mathematics or Biology to refer to the students' course of study, while second M or F refers to male or female respectively. The number indicates the identification number of the student in that particular class and it varies from class to class. For example, MM1 in PH1 and MM1 in PH3 refer to different students.

The lecture discourse was examined carefully to identify instances of student-lecturer interaction, mainly the interactional exchanges were identified with special attention to the questions that initiated the interactional exchange or episodes. The rest of the section explains this identification and finally sums up telling how an analytical framework was developed.

\section{Developing an Analytical Framework for FS Lecture Discourse}

\subsection{Important Analytical Components of a Lecture Discourse and the Relative Importance of Each of Them}

The objective of the study being the identification of dialogic teaching, a method is needed to identify the existing dialogic discourse in the lectures so that the whole lecture can be categorized into dialogic or monologic. Traditionally, interaction is considered as a dialogue between a teacher and students or between students, until the concept dialogic came into existence in lecture discourse. As it was mentioned in the introduction, an interaction can be a recitation script or a dialogic interaction. The latter refers to mutual construction of discourse by the teacher and students, more importantly both contribute to the development of the discourse. For example, from the AP lecture the following episode (Note 1) is found. This episode starts with an initiation move (Iusually teacher's questions), and answered by students (Response- R) and usually ends with an evaluation (E) by the lecturer. But here it is extended due to a clarification request $(\mathrm{CR})$ made by the lecturer.
BL1: what is our mean body temperature $\uparrow$ ?
-Initiation
SAC: ninety-eight point four
(R) -Response

BL1: ninety-eight point four what $\uparrow$ ? Fahrenheit or Centigrade $\uparrow$ ? (CR $+\mathrm{I})$-Clarification Request

SAC: Fahrenheit

(R)

BL1: Fahrenheit

$$
\text { (E- Evaluation - acceptance) }
$$

(From the AP lecture)

This episode is considered interactive because the teacher and students involve in a dialogue but the teacher does not co-construct the lesson using students' knowledge. Hence, she is asking a display question only. As Tharp and Gallimore (1988) explain, this is a recitation in which one-to-one question and answer sequences exist.

Conversely, in another extract, the lecturer and students try to co-construct the lesson, trying to define what the term 'quality' is. This episode can be considered dialogic, because dialogic interaction gives equal roles to students in the classroom. The episode below from the lecture AS unfolds with a discussion of a concept 'quality' and continues up to 65 moves.

ML2: [...] now next I am going to teach you what is the definition of quality-definitions of quality what is quality? because — ok you can - this - theoretical definition is there when I ask you just what is quality what you can say? what is quality? [5] what is quality? [7] (I - I - I - I) I - Initiation Move
1) MM5:
better than
(R partial)
2) ML2:
sorry- better
3) MM5:
better than the
(R partial)
4) ML2:
better than the- sorry
(CR)
5) MM5:
anybody
(R)
6) ML2: /uh/?

$\mathrm{R}$ - Response Move

$\mathrm{CR}$ - Clarification Request 
7) MM5: better than the bad body

8) ML2: better than- one- better than the

9) MM5: better than something

10) ML2: better than something-ok-better than something-ok-now-I am asking-you-go to - go to some textiles and buying a shirt and saying it is a quality shirt what does it mean the quality shirt?

(F) F- Feedback Move

As we can see in these examples, the teacher's questions decide the subsequent discourse development. When the teacher asks a display question, for which answer is known, the exchange stops in three moves. If a teacher asks a referential question, for which the teacher expects answer from students, the dialogue builds on. Hence, the nature of the questions decides the way the discourse moves, as explained below. Therefore, in this study, in the process of finding an analytical framework to analyse the lecture discourse, two components become important. They are (1) the lecturers' questions which are the trigger for the development of lecturer-student interactions and the other one is (2) the pattern of interactional exchanges that is developed as a result of lecturers' questions. These two can be used to decide the overall lecture discourse in terms of its dialogicality. The rest of the section explains how this is done.

\subsection{Importance of Teachers' Questions}

Chin (2007) argues that in content classes questions are believed to contribute towards the meaning making process by way of teacher talk and teacher-student interaction. Questions have always been an important interactional tool used by teachers to activate and facilitate the learning process (Crawford Camicittoli, 2008). The types of questions lecturers ask may decide the nature of the discourse. If the questions are open and warrant students' contribution, they can generate a lot of interaction, ideas and finally lead to better understanding of the subject under discussion, whereas the questions which require only a short answer or 'yes or no' answer would not be able to help build a discussion in the class. Chin (2006) asserts that early studies on teacher questioning focus on the IRF (Initiation/ lecturer's question-Response-Feedback) pattern of discourse (e.g., Mehan, 1979; Lemke, 1990), whereas recent studies focus on students' construction of knowledge (e.g., Yip, 2004; Chin, 2007). Therefore, traditionally teachers ask questions to find what students knew. Any deviant idea from the teachers' pre-planned agenda is either rejected or discouraged. However, recent studies have shown that in content classes a question is a good way to introduce a problem and warrant the contribution from the students (Nassaji \& Wells, 2000).

Yip (2004) identifies ten types of questions under four categories used by trainee biology teachers in an L1 high school biology class. Those four categories are (1) lower order questions, (2) higher order questions, (3) motivation questions and (4) conceptual change questions. Lower order questions are used for recalling facts and explanations, while higher order questions are used for analysis, evaluation and synthesis.

Chin (2007) investigated how teachers use questions in the class to scaffold students' thinking and construct scientific knowledge. In her study with grade 7 school children she identified four questioning approaches adopted by teachers. They are Socratic questioning, verbal jigsaw, semantic tapestry and framing. All these questioning techniques focused on how teachers use questions to guide students' thinking, develop a concept, etc.

In another study, van Zee and Minstrell (1997) found how physics teachers use questions to guide students' thinking. They work with a particular strategy called 'reflective toss'. This is a kind of a questioning technique that involves students in deeper thinking.

Carefully observing the lecture discourse data occurring at FS, and based on the literature on questions, the questions lecturers ask at FS could be classified into two categories (1) Concept Development Questions (CDQs) and (2) Other Types of Questions (OTQs). Of these two, the Concept Development Questions are an important category since CDQs could help developing the dialogic discourse, as explained below. An earlier version of this analysis is found in researcher's doctoral research work (Navaz, 2012).

\subsubsection{Concept Development Questions (CDQs)}

These types of questions are asked by the lecturers as open-ended questions to get different views of the students in order to develop a particular concept or a theme. 'The teacher asks conceptual questions to elicit students' ideas and facilitate productive thinking, invites and welcomes students' responses and questions [...]' (Chin, 2007, p. 817). Also, it is believed that during guided discussions, teachers primarily ask conceptual questions to elicit students' thinking (van Zee et al., 2001). These questions are similar to open-ended referential questions 
and also to Bloom's synthesis questions. e.g., What is quality? (from the AS lecture extract)

The second broader category, Other Types of Questions (OTQs), includes 2) Knowledge Testing Questions (KTQs) 3) Knowledge Application Questions (KAQs) and 4) Classroom Management Questions (CMQs).

\subsubsection{Knowledge Testing Questions (KTQs)}

Knowledge Testing Questions are used to check the students' subject knowledge that has been gained in the lectures. They are mostly display type questions and usually require a short answer. Also, they are similar to factual recall questions, which ask the students to name, identify, recall, define, etc., and the emphasis is on memory or observation (Ellis, 1993). Many of the KTQs have low cognitive demand. e.g., What is biotechnology? (from BT lecture)

\subsubsection{Knowledge Application Questions (KAQs)}

These questions do not test the knowledge of the students but test how the knowledge could be applied to solve a problem. Usually these questions are used when the lecturers give tasks/worksheets to be solved in the class. This is similar to Myhill's process questions. Using process questions the teacher can check on the understanding of the learning process or students could explain their thinking (Myhill, 2006), e.g., How do you find the value of R? (From the PH lecture)

It is, however, difficult to differentiate the questions from their appearance as KTQs or KAQs but it is from the subsequent function of the discourse we can categorise the question.

\subsubsection{Classroom Management Questions (CMQs)}

These questions are not connected with the teaching or learning of the direct content subject. They usually deal with management and organisation of related academic activities like submitting assignments, arranging a practical class, etc. (Myhill, 2006). They are similar to the classroom procedural questions (Richards \& Lockheart, 1996), e.g., Did you submit the assignment? (from the BT lecture)

In the FS discourse, the following questions were found, as shown in Table 2. There were many KTQs and a few CDQs which have the potential of creating dialogic episodes.

Table 2. Types of questions across all 12 lectures

\begin{tabular}{ll}
\hline Types of Questions Initiated Interaction & Number \\
\hline KTQ & 28 \\
KAQ & 20 \\
CDQ & 06 \\
CMQ & 03 \\
Total & $\mathbf{5 7}$ \\
\hline
\end{tabular}

Having described four types of questions that have been identified in the lecture discourse, the system to classify the interactional episode is described next.

\subsection{Developing a Classification System for Patterns of Interactional Episodes/Exchanges}

The interactional pattern could be nuclear or extended. The nuclear exchange is a three (usually) part exchange which occurs with I-R and F, but this move could be optional. Mehan (1979) explains these extended sequences which occur with an Initiation and take several extended moves as a result of Feedback (i.e., can you elaborate further?) given by the teacher instead of Evaluation (i.e., good). Nassaji and Wells (2000) also explain the nuclear and extended sequences. A nuclear exchange occurs with I and R, with an optional F. Several nuclear exchanges together make the extended sequence, and are called episodes in this study. Many of the studies that deal with primary level or secondary level school classrooms discourse were found to possess the IRF structure.

In the next section, I am going to talk about the types of interactional episodes. These types of episodes are used in the process of identifying the overall lecture discourse only, while the patterns we just discussed are used to describe the interactional episodes.

Mortimer and Scott (2003) and Scott, Mortimer and Aguiar (2006) identify a framework to analyse the individual episodes of the L1 science lessons of the secondary school classrooms. The central component of their framework is the communicative approach by which they mean the overall pattern of the classroom discourse. This communicative approach is constructed based mainly on whether the teacher interacts with the students (interactive/non-interactive) and whether the teacher takes others' view into consideration or delivers the lesson 
as a monologic (dialogic/authoritative). As a result, they present four types of discourse which they devise by combining the above mentioned two criteria: dialogic/authoritative and interactive/non-interactive, as given below (Table 3). The approach seems to have a broader analytical coverage of lecture discourse on those two different dimensions. Scott, Mortimer and Aguiar (2006) claim that by authoritative discourse they mean "the teacher's purpose is to 'focus the students' full attention on just one meaning', while dialogic discourse 'takes into account a range of students', and others' ideas" (2006, p. 610).

Table 3. Mortimer and Scott's (2003) framework to analyse lecture discourse

\begin{tabular}{ll}
\hline Interactive/dialogic & Non-interactive/dialogic \\
Interactive/authoritative & Non-interactive/authoritative \\
\hline
\end{tabular}

The work by Scott, Mortimer and colleagues seems reasonably appropriate for the present study as their proposed framework has a consideration for dialogic discourse in addition to interactive discourse. However, their framework is applicable to the interactional episodes within a lesson, not to the whole lesson or lecture which is required in the present study context.

As an alternative, the MICASE categories of discourse could be reviewed. The MICASE corpus is a spoken language corpus of approximately 1.8 million words (nearly 200 hours). It analyses various speech events of the selected disciplines of the University of Michigan in Ann Arbor, Michigan (Simpson-Vlach \& Leicher 2006). The MICASE corpus identifies five categories to classify speech events (e.g., a lecture) with two extremes: highly monologic and highly interactive, as shown in the Table 4 below.

Table 4. MICASE classification system of speech events

\begin{tabular}{ll}
\hline Category & Description \\
\hline Highly Monologic & One speaker monopolizes the floor in a lecture, occasionally with a few questions or brief comments. \\
Mostly Monologic & Primarily monologic discourse interspersed with some segments of interactive discourse. \\
Mixed & No one discourse mode is predominant. \\
Mostly Interactive & Primarily interactional discourse involving two or more speakers, interspersed with some longer segments of \\
& monologic discourse. \\
Highly Interactive & Highly interactional discourse involving two or more speakers, with shorter turns and no monologic segments. \\
\hline Source: Simpson-Vlach and Leicher, 2006.
\end{tabular}

MICASE classification is applicable for whole lectures but it does not consider the dialogic/authoritative categories, like Mortimer and Scott's (2003).

Another problem with MICASE is the operationalisation of the MICASE categories. For example, one of the MICASE categories 'mostly monologic' is defined as 'a lecture which is primarily monologic discourse interspersed with some segments of interactive discourse'. Here the word 'some' is an abstract property and it cannot be easily quantified looking at a lecture discourse. That is, 'some' does not describe what number or what duration. This confusion is applicable to other categories of MICASE too. Therefore, though features of MICASE seem to be a suitable classification system for the present lecture discourse, there are two kinds of inherent problems if one is to use the MICASE system. One is the lack of accountability of the dialogic discourse and the other one is the difficulty in the operationalisation of the MICASE categories. Hence, a slightly modified system would overcome these two practical difficulties and could yield a system that is suitable for the classification of overall lecture discourse at FS.

In order to overcome the problem of the operationalisation of the MICASE categories, the total duration of interactional episodes could be considered, as explained below.

\subsection{Developing a Classification System for the Types of Overall Lecture Discourse at FS}

Different classification systems of lecture discourse are available. Nevertheless, the classification of discourse is carried out at different levels, mainly at episode level (i.e., Mortimer \& Scott, 2003) and at lecture level (i.e., MICASE manual, 2002). An episode is a collection of exchanges, or sometimes a single exchange also makes an episode. At the same time, the classification of episodes and lectures are interconnected. One cannot classify the lecture discourse without identifying the type of interactional episodes, their duration, etc. Only based on the predominant type of interactional episodes can one classify the lecture discourse as in the case of MICASE. 
Therefore, the interactional episodes in this study are classified based on the questions that initiated the episodes. Therefore, there are episodes initiated with CDQs, as well as OTQs (KTQ, KAQ or CMQ) and similarly the episodes are identified as Concept Development Episodes (CDEs), or OIEs (Other Interactional Episodes) that cover Knowledge Testing Episodes (KTEs), Knowledge Application Episodes (KAEs) or Classroom Management Episodes (CMEs)).

The duration of each interactional episode found in the respective lecture discourse was measured from the lecture recordings and are given below in Table 5 .

Table 5. Comprehensive details of the lecture (Lec) discourse

\begin{tabular}{llll}
\hline Lecture Identification & No. of interactional episodes & $\begin{array}{l}\text { Total duration of interactional } \\
\text { episodes }\end{array}$ & $\begin{array}{l}\text { Types of questions used to initiate } \\
\text { the interactional episodes }\end{array}$ \\
\hline Physics Lec 1 (PH 1) & 7 & 12.20 & 7 KTQs \\
Physics Lec 3 (PH 3) & 8 & 17.40 & $\begin{array}{l}\text { 1 CMQs, 3 KTQs, 3 KAQs, 1 } \\
\text { student-initiated question }\end{array}$ \\
& & & $2 \mathrm{KTQs}$; KAQ \\
Physics Lec 5 (PH 5) & 3 & 6.40 & 3 KTQs \\
Biotechnology Lec 1(BT 1) & 3 & 9.20 & $7 \mathrm{KTQs}$, 1 CMQ \\
Biotechnology Lec 3 (BT 3) & 8 & 10.30 & $4 \mathrm{KTQs}$; CDQ \\
Biotechnology Lec 4 (BT 4) & 5 & 14.50 & 4 CDQs; 4 KAQs \\
Applied Statistics Lec 1 (AS 1) & 8 & 22.30 & $2 \mathrm{KTQs}$ 5 KAQs; 1 CMQ \\
Applied Statistics Lec 3 (AS 3) & 8 & 23.10 & 1 CDQ, 5 KAQs; 1 CMQ; 1 KTQ \\
Applied Statistics Lec 4 (AS 4) & 8 & 11.10 & $4 \mathrm{KTQs}$ \\
Animal Physiology Lec 1 (AP 1) & 4 & 2.10 & 1 KTQ \\
Animal Physiology Lec 3 (AP 3) & 1 & 0.15 & $2 \mathrm{KTQs}$; KAQs \\
Animal Physiology Lec 4 (AP 4) & 4 & 2.40 & \\
\hline
\end{tabular}

In addition, duration of each interactional episode was measured and is presented below in Table 6 .

Table 6. Duration of different interactional episodes and the total duration

\begin{tabular}{lllllll}
\hline \multirow{2}{*}{ Lecture } & \multicolumn{7}{l}{ Duration of different episodes } & & \multicolumn{2}{l}{$\begin{array}{l}\text { Total duration of } \\
\text { interactional exchanges }\end{array}$} \\
\cline { 2 - 6 } & CDE & \multicolumn{1}{l}{ KTE } & KAE & CME & Other & 12.20 \\
\hline PH 1 & -- & 12.20 & -- & -- & -- & 17.40 \\
PH 3 & -- & 4.30 & 10.40 & 0.10 & 2.20 (Note 2) & 6.40 \\
PH 5 & -- & 6.30 & 0.10 & -- & -- & 9.20 \\
BT 1 & -- & 9.20 & -- & -- & -- & 10.30 \\
BT 3 & -- & 10.10 & -- & 0.20 & -- & 14.50 \\
BT 4 & 6.20 & 9.30 & -- & -- & -- & 22.30 \\
AS 1 & 16.20 & -- & 6.40 & -- & 0.30 (Note 3) & 23.10 \\
AS 3 & -- & 0.20 & 22.40 & 0.10 & -- & 11.10 \\
AS 4 & 1.40 & 1.50 & 7.20 & 0.20 & -- & 2.10 \\
AP 1 & -- & 2.10 & -- & -- & -- & 0.15 \\
AP 3 & -- & 0.15 & -- & -- & -- & 2.40 \\
AP 4 & -- & 0.20 & 2.20 & -- & -- & $\mathbf{1 3 2 . 1 0}$ \\
Total & $\mathbf{2 3 . 2 0}$ & $\mathbf{5 6 . 1 5}$ & $\mathbf{4 9 . 5 0}$ & $\mathbf{1 . 0}$ & $\mathbf{2 . 5 0}$ & \\
\hline
\end{tabular}

At the beginning, the total duration of interactional episodes would be a suitable indicator to mark the extent to which the lecturers and students interact with each other. This is preferable to a classification system that uses the number of questions asked (e.g., Morell, 2004) because the number does not give a clear idea of the intensity of the interaction which takes place. In addition, to operationalise the MICASE categories some assertions are needed. The duration of the lecture hour at FS is one hour and the total average talking time of the 12 transcribed lectures is 53 minutes. Considering 50 as the maximum duration of interaction that would possibly take place in a single lecture, five interactive categories could be assigned with five scales as shown below in Table 7. 
Table 7. Assigning duration to MICASE categories

\begin{tabular}{ll}
\hline MICASE categories & Value assigned with total duration of interactional episodes (minutes) \\
\hline Highly Monologic & $<10$ \\
Mostly Monologic & $10-20$ \\
Mixed Lectures & $21-30$ \\
Mostly Interactive & $31-40$ \\
Highly Interactive & $>40$ \\
\hline
\end{tabular}

Now based on the duration of the total interactional episodes of each lecture, its overall discourse type could easily be decided. For example, if a lecture's total duration of interactional episodes is 15 minutes, it can be classified as mostly monologic. However, now attention should also be paid to the second problem with MICASE - lack of dialogic value of the discourse. In order to consider the dialogic values within interactive lectures, a conditional sub category could be made within interactive lectures. The basic consideration is that for a lecture to be dialogic it should have interactional episodes of the concept development category. The interactional episodes in this study are classified based on the questions that initiated the episodes. There are episodes identified as Concept Development Episodes (CDE), and Other Interactional Episodes (OIE). Hence, Concept Development Episodes (CDE) (an example is given in the appendix), in comparison, have the potential to incorporate the students' views into knowledge building.

Therefore, a lecture which is mostly or highly interactive has a substantial amount of lecturer-student interaction. In addition, if the CDEs predominate in the total interactional episodes, those lectures could be classified as dialogic. Or else if other episodes (OIEs) predominate in the discourse, they are considered interactive (or non-dialogic) only.

The new framework developed for the current study has categories, similar to MICASE, from monologic to dialogic lectures and in between a category called mixed lectures. In addition, it has two more categories within the dialogic lectures: mostly dialogic and highly dialogic. These two would be alternative categories to both mostly interactive and highly interactive respectively. If a highly interactive lecture contains a higher duration of CDEs over other episodes, it is called highly dialogic. Similarly, mostly interactive lectures can become mostly dialogic, when CDEs predominate in their discourse, as shown in Table 8 below.

Table 8. The framework for the analysis of the FS overall lecture discourse

\begin{tabular}{lll}
\hline \multicolumn{2}{l}{ Duration of total interactional episodes (minutes) } & Discourse category of lecture (Note 4) \\
\hline$<10$ & -- & Highly Monologic \\
$10-20$ & -- & Mostly Monologic \\
$21-30$ & -- & Mixed Lectures \\
$31-40$ & Other types of episodes predominates the discourse & Mostly Interactive \\
& CDE predominates the discourse & Mostly Dialogic \\
$>40$ & Other types of episodes predominates the discourse & Highly Interactive \\
& CDE predominates the discourse & Highly Dialogic \\
\hline
\end{tabular}

As a summary, the proposed framework, similar to MICASE, has five categories: highly monologic, mostly monologic, mixed, mostly interactive and highly interactive. However, unlike MICASE, this study considers the dialogic teaching too as a key feature for successful lecture delivery and therefore, within the interactive categories it introduces two alternative categories. They are mostly dialogic and highly dialogic. In addition, they are decided based on the presence of CDE and other types of episodes.

\subsection{An Alternative Approach to Analysing Discourse}

For a practitioner like a teacher or a lecturer, applying this framework would be time consuming and therefore, an alternative approach could also be adopted. Instead of five categories, the teachers could go for four broad categories: Monologic, Mixed, Interactive and Dialogic. These categories are devised based on the presence of approximate duration of the interactional episodes, as shown in Table 9. 
Table 9. Alternative measure of analytical framework

\begin{tabular}{|c|c|}
\hline Proportion of interactional episodes & Discourse category of lecture (Note 5) \\
\hline $\begin{array}{l}\text { Only a few interactional episodes and they last less than } 1 / 3 \text { of the lecture hour OR completely } \\
\text { absent }\end{array}$ & Monologic lectures \\
\hline Interactive categories of any kind of episodes that last nearly $1 / 3$ to $1 / 2$ of the lecture duration & Mixed Lectures \\
\hline Other types of episodes (OIEs) predominate the discourse more than $1 / 2$ of the lectures & Interactive lectures \\
\hline CDEs predominate the discourse more than $1 / 2$ of the lecture duration & Dialogic lectures \\
\hline
\end{tabular}

Monologic lectures: They are full of longer lecture talks with a few interactional episodes that last only less than $1 / 3$ of the lecture. Or else, the interaction could be absent in lectures.

Mixed lectures: Nearly one-third of a half of the lesson time is filled with interactional episodes of any kind.

Interactive lectures: These lectures are with a series of sporadic questions and answers which make up the OIEs. The interactional episodes also reflect the IRF (Initiation-Teacher's questions, Response by the students and F-feedback by the students) across the lectures. Nearly more than a half of the lesson time is filled with such interactional episodes.

Dialogic lectures: There are interactional episodes that extend beyond the recitation scripts. These episodes are longer and lead to knowledge building or knowledge construction across a single lecture. Nearly more than half of the lesson time is filled with Concept Development Episodes (CDEs).

Moreover, according to the analytical framework developed for this study to classify the 12 transcribed lectures, there were two mixed lectures, five mostly monologic and five highly monologic lectures. As far as the lecture delivery at FS is concerned, it was mostly teacher-centered. Lecturers conducted the lectures as monologic trying to cover the content material within the stipulated time, though their individual styles varied.

\section{Limitations of the Framework}

In this study, the analytical framework was developed on the assumption that lectures are conducted for an hour at each contact, considering the FS situation. In case, when lectures are conducted longer than an hour, the analysis should be done based on each hour only. Also, one should keep in mind that the presence of CDEs cannot be assumed to always bring lengthy answers from students, though using CDEs one can generate extended sequence of interaction, when other conditions are favourable (e.g., cooperation from students).

Deciding on the types of questions and episodes may be influenced by personal judgement which may affect the classification of the types of lecture discourse. Another researcher or a colleague can be asked to identify the question types and inter-rater reliability can be maintained. Also, calculating duration of individual episodes is a laborious task and may consume a lot of researcher's time. When there is a time limitation, practitioners could adopt the alternative approach to get an idea of their lecture discourse. Despite these constraints, there are merits too as explained under implications below.

\section{Implications of the Framework Developed}

The analytical framework developed in this study can be applied to the lecture discourse to investigate the extent to which dialogic teaching is practised in other larger universities in Sri Lanka as well as further afield. This study unearths the dialogic teaching in an L2 context at tertiary level in the absence of other studies in Asian countries. In addition, the analytical framework can be used to categorise individual lecturers' lecture delivery in terms of dialogic interaction. That is, the lecture delivery can be categorised from student-centered (highly/mostly dialogic lecture delivery) to teacher-centered (highly/mostly monologic lecture delivery). This categorisation can be used as a basis for teacher preparation which helps lecturers become equipped with the skills to move to a highly/mostly dialogic lecture delivery. Walsh (2011) argues for the importance of analysing classroom talk and more importantly asserts teachers to have access to their own classroom talk analysed so that it may lead to better practice. Nevertheless, one should not forget the difficulties in developing dialogic discourse in the classrooms. Lyle states 'despite the evidence of positive impact, however, there is a well-established and long line of research which suggests that the establishment of dialogic approaches to classroom discourse will not be easy' (Lyle, 2008, p. 236).

The studies that have investigated the lecture corpus for interactivity, like that of the MICASE corpus, are few in number even in the Western countries. For example, the ELC (Engineering Lecture Corpus) compiled by Coventry University, UK covers Engineering lectures from three universities: Coventry University in the UK, University of Teknologi Malaysia (UTM) in Malaysia, and Auckland University of Technology (AUT) in New Zealand. But, the corpus developers have not analysed the corpus in terms of interactivity. It is the same for the 
BASE corpus too. In addition, more academic spoken corpus-based studies can be envisaged in the future as the researchers in different countries have recently focused on this. CUCASE, NUCASE and EDASE corpora are being compiled and there are not yet any published results. Moreover, these corpora have rarely considered dialogic interaction in their studies of the lecture corpus, even Pedrosa de Jesus and da Silva Lopes $(2009,2011)$, the only known researchers to investigate dialogic interaction at tertiary level L1 classes, did not categorise their lecture corpus for dialogic interaction. Therefore, to my knowledge the present study has attempted to have categorised the lecture corpus in terms of dialogic interaction, albeit on a small scale.

Therefore, the findings of the study can have wider implications. It could contribute to both practitioner perspectives as well as to a new knowledge domain. From a practitioner perspective, the new analytical framework developed in this study can be used by anyone who would like to evaluate his or her own lecture delivery or by any teacher developers who would like to investigate other practitioners' classes through observation. Hence, the findings from the framework would tell the teachers how they should reorient their lecture delivery for reaching the dialogic value. In Sri Lanka, this change should take place gradually through ample opportunities for teachers to get to know about the importance of dialogic delivery and the mechanisms to develop it.

\section{Conclusion}

The analytical framework developed in this study refines and extends the MICASE corpus interactivity rating in a contextually-focused way. In particular, it overcomes the two inherent problems found in the MICASE system of analysis for interactivity. They are the use of arbitrary values for classifying lectures and lack of consideration for dialogic value. This study, which considers dialogic interaction to be at the heart of its analytical framework, has developed an analytical framework that uses exact duration of interactional episodes along with the consideration of dialogic episodes. As a result, it can be considered more suitable to assess any lecture delivery in an EMI context with NNS (Non-Native Speaker) students.

The analytical framework developed in this study could be used in future research studies and more importantly in teacher preparation activities to identify favourable lecture delivery, as mentioned earlier. The framework as a basis can be used to indicate the gap between the present level of interactivity in lectures and the desired level and can be of considerable value to the teaching and learning in higher education. Therefore, this study being the first to unearth the practising of dialogic interaction at tertiary level undergraduate classes, using the specially designed analytical framework, can make a concrete contribution to teaching and learning in higher education, mainly to the concept of developing content and language development through dialogic lecture delivery at tertiary level L2 content classes.

\section{References}

Alexander, R. (2006). Towards Dialogic Teaching: Rethinking Classroom Talk. York: Dialogos.

Bakhtin, M. M. (1981). The Dialogic Imagination. Austin. Texas: University of Texas Press.

Barnes, D. (2008). Exploratory talk for learning. In S. Hodgkinson \& N. Mercer (Eds.), Exploring Talk in Schools (pp. 1-15). London: Sage. https://doi.org/10.4135/9781446279526.n1

Chin, C. (2006). Classroom Interaction in Science: Teacher questioning and feedback to students' responses. International Journal of Science Education, 28(11), 1315-1346. https://doi.org/10.1080/09500690600621100

Chin, C. (2007). Teacher questioning in science classrooms: Approaches that stimulate productive thinking. Journal of Research in Science Teaching, 44(6), 815-843. https://doi.org/10.1002/tea.20171

Crawford Camiciottoli, B. (2008). Interaction in academic lectures vs written text materials: The case of questions. Journal of Pragmatics, 40, 1216-1231. https://doi.org/10.1016/j.pragma.2007.08.007

Ellis, K. (1993). Teacher questioning behaviour and student learning: What research says to teachers. Paper presented at the Annual Meeting of the Western States Communication Association, Albuquerque, NM, 12-16 February, 1993.

Gibbons, P. (2003). Mediating language learning: Teacher interactions with ESL students in a content-based classroom. TESOL Quarterly, 37(2), 247-273. https://doi.org/10.2307/3588504

Gibbons, P. (2015). Scaffolding language, scaffolding learning: Teaching English Language Learners in the mainstream classroom (2nd ed.). Portsmouth, NH: Heinemann.

Gupta, A., \& Lee, G. L. (2015). Dialogic Teaching Approach with English Language Learners to Enhance Oral 
Language Skills in the Content Areas. International Journal of Language and Linguistics, 2(5), 10-17. Retrieved from https://digitalcommons.odu.edu/teaching-learning_fac_pubs/19

Hall, J. K., \& Verplaetse, L. S. (Eds). (2000). Second and Foreign Language Learning through Classroom Interaction. Mahwah, NJ: Lawrence Erlbaum. https://doi.org/10.4324/9781410605498

Haneda, M. (2005). Some functions of triadic dialogue in the classroom: Examples from L2 research. The Canadian Modern Language Review, 62(2), 313-333. https://doi.org/10.1353/cml.2006.0003

Haneda, M., \& Wells, G. (2010). Learning science through dialogic inquiry: Is it beneficial for English-as-additional-language students? International Journal of Educational Research, 49, 10-21. https://doi.org/10.1016/j.ijer.2010.05.003

Hennessy, S., Rojas-Drummond, S., Higham, R., Marquez, A. M., Maine, F., \& Ríos, R. M. (2016). Developing a coding scheme for analysing classroom dialogue across educational contexts. Learning, Culture and Social Interaction, 9, 16-44. https://doi.org/10.1016/j.lcsi.2015.12.001

Hiltunen, M., Kärkkäinen, S., \& Keinonen, T. (2020). Biology student teachers' dialogic talk in inquiry-based instruction. Journal of Biological Education, 54(3), 300-314. https://doi.org/10.1080/00219266.2019.1575264

Juuti, K. L., \& Lavonen, J. (2019). Interest in Dialogic and Non-Dialogic Teacher Talk Situations in Middle School Science Classroom. International Journal of Science and Mathematics Education. https://doi.org/10.1007/s10763-019-10031-2

Lehesvuori, S., Chan, K. H. C., Ramnarain, U., \& Viiri, J. (2017). In Search of Dialogicity: A Comparison of Curricular Documents and Classroom Interactions from Finland and Hong Kong. Education Sciences, 7(76), 1-16. https://doi.org/10.3390/educsci7040076

Lemke, J. L. (1990). Talking science: Language, learning, and values. Ñorwood, NJ: Ablex.

Lyle, S. (2008). Dialogic Teaching: Discussing Theoretical Contexts and Reviewing Evidence from Classroom Practice. Language and Education, 22(3), 222-240. https://doi.org/10.1080/09500780802152499

Maria Vrikki, R. K., Elisa, C., Sara, H., Lisa, L., Flora, H., Nube, E., \& Farah, A. (2019). The teacher scheme for educational dialogue analysis (T-SEDA): developing a research-based observation tool for supporting teacher inquiry into pupils' participation in classroom dialogue. International Journal of Research \& Method in Education, 42(2), 185-203. https://doi.org/10.1080/1743727X.2018.1467890

Matusov, E. (2009). Journey into dialogic pedagogy. New York: Nova Science Publishers.

Mehan, H. (1979). Learning Lessons: Social Organization in the Classroom. Cambridge, MA: Harvard University Press.

Mercer, N. (1995). The Guided Construction of Knowledge: Talk Amongst Teachers and Learners. Clevedon: Multilingual Matters.

Mercer, N. (2001). Language for teaching a language. In C. Candlin \& N. Mercer (Eds.), English Language Teaching in its Social Context: A Reader (pp. 243-257). New York, NY: Routledge.

Mercer, N., Dawes, L., \& Staarman, J. K. (2009). Dialogic teaching in the primary science classroom. Language and Education, 23(4), 353-369. https://doi.org/10.1080/09500780902954273

Molinari, L., \& Mameli, C. (2010). Classroom dialogic discourse: An observational study. Procedia Social and Behavioral Sciences, 2, 3857-3860. https://doi.org/10.1016/j.sbspro.2010.03.604

Morell, T. (2004). Interactive lecture discourse for university EFL students. English for Specific Purposes, 23, 325-338. https://doi.org/10.1016/S0889-4906(03)00029-2

Mortimer, E. F. (1998). Multivoicedness and univocality in classroom discourse: An example from theory of $\begin{array}{llll}\text { matter. International Journal of Science Education, 20(1), 67-82, } & \end{array}$ https://doi.org/10.1080/0950069980200105

Mortimer, E. F., \& Machado, A. H. (2000). Anomalies and conflicts in classroom discourse. Science Education, 84, 429-444, https://doi.org/10.1002/1098-237X(200007)84:4<429::AID-SCE1>3.0.CO;2-\#

Mortimer, E. F., \& Scott, P. H. (2003). Meaning Making in Secondary Science Classrooms. Maidenhead, UK: Open University Press.

Myhill, D. (2006). Talk, talk, talk: Teaching and learning in whole class discourse. Research Papers in Education, 
21(1), 19-41. https://doi.org/10.1080/02671520500445425

Nassaji, H., \& Wells, G. (2000). What's the use of triadic dialogue. Applied Linguistics, 21(3), 376-406. https://doi.org/10.1093/applin/21.3.376

Nathan, M. J., Kim, S., \& Grant, T. S. (2009). Instituting change in classroom discourse structure: Human and computer-based motif analysis (WCER Working Paper No. 2009-1). Madison: University of Wisconsin-Madison, Wisconsin Center for Education Research.

Navaz, A. M. M. (2012). Lecturer-Student Interaction in English-Medium Science Lectures: An Investigation of Perceptions and Practice at a Sri Lankan University where English is a Second Language. Unpublished $\mathrm{PhD}$ Thesis, University of Nottingham. Nottingham etheses. Retrieved from http://eprints.nottingham.ac.uk/12995/

Navaz, A. M. M. (2013). A study on perception of lecturer-student interaction in English- medium science lectures. Novitas-ROYAL (Research on Youth and Language), 7(2), 117-136.

Navaz, A. M. M. (2014). Student Centred Learning: Are our students and lecturers ready to embrace this approach? Paper published at the conference handbook of the Third International Symposium of the South Eastern University of Sri Lanka, August 2014. Retrieved from http://www.seu.ac.lk/researchandpublications/symposium/4th/socilascienceshumanities/Student\%20Centred $\% 20$ Learning.pdf

Pedrosa de Jesus, M. H., \& da Silva Lopes, V. (2009). Classroom questioning and teaching approaches: A study with Biology undergraduates. In G. Çakmakci \& M. F. Taşar (Eds.), Contemporary Science Education Research: Scientific Literacy and Social Aspects of Science (pp. 33-39). Istanbul: Pegem Akademi.

Pedrosa de Jesus, M. H., \& da Silva Lopes, B. (2011). The relationship between teaching and learning conceptions, preferred teaching approaches and questioning practices. Research Papers in Education, 26(2), 223-243. https://doi.org/10.1080/02671522.2011.561980

Prakash, E. S. (2010). Explicit constructivism: A missing link in ineffective lectures? Advanced Physiological Education, 34, 93-96. https://doi.org/10.1152/advan.00025.2010

Richards, J. C., \& Lockheart, C. (1996). Reflective Teaching in Second Language Classrooms. Cambridge: Cambridge University Press.

Rojas-Drummond, S., \& Mercer, N. (2003). Scaffolding the development of effective collaboration and learning. International Journal of Educational Research, 39, 99-111. https://doi.org/10.1016/S0883-0355(03)00075-2

Sedova, K. (2017). A case study of a transition to dialogic teaching as a process of gradual change. Teaching and Teacher Education, 67, 278-290, https://doi.org/10.1016/j.tate.2017.06.018

Scott, P. (1998). Teacher talk and meaning making in science classrooms: A Vygotskian analysis and review. Studies in Science Education, 32(1), 45-80. https://doi.org/10.1080/03057269808560127

Scott, P. H., Mortimer, E. F., \& Aguiar, O. G. (2006). The tension between authoritative and dialogic discourse: A fundamental characteristic of meaning making interactions in high school science lessons. Science Education, 90, 605-631. https://doi.org/10.1002/sce.20131

Simpson-Vlach, R. C., \& Leicher, S. (2006). The MICASE Handbook: A Resource for Users of the Michigan Corpus of Academic Spoken English. Ann Arbor, MI: University of Michigan Press. https://doi.org/10.3998/mpub.101203

Skidmore, D. (2000). From Pedagogical Dialogue to Dialogical Pedagogy. Language and Education, 14(4), 283-296. https://doi.org/10.1080/09500780008666794

Staarman, J., \& Mercer, N. (2010). The Guided construction of knowledge: Talk between teachers and students. In K. Littleton, C. Wood \& J. K. Staarman (Eds.), International Handbook of Psychology (pp. 75-104). Bingley: Emerald Group Publishing Limited.

Swain, M., \& Lapkin, S. (1998). Interaction and second language learning: Two adolescent French immersion students working together. The Modern Language Journal, 82(3), 320-337. https://doi.org/10.1111/j.1540-4781.1998.tb01209.x

Taylor, D. L., \& Lelliott, A. D. (2015). Dialogic Talk in Diverse Physical Science Classrooms. African Journal of Research in Mathematics, Science and Technology Education, 19(3), 255-266. 
https://doi.org/10.1080/10288457.2015.1089678,

Tharp, R. G., \& Gallimore, R. (1988). Rousing Minds to Life: Teaching, Learning, and Schooling in Social Context. Cambridge: Cambridge University Press. https://doi.org/10.1017/CBO9781139173698

Trigwell, K., Prosser, M., \& Waterhouse, F. (1999). Relations between teachers' approaches to teaching and students' approaches to learning. Higher Education, 37, 57-70. https://doi.org/10.1023/A:1003548313194

van Zee, E. H., Iwasyk, M., Kurose A., Simpson, D., \& Wild, J. (2001). Student and teacher questioning during conversations about science. Journal of Research in Science Teaching, 38(2), 159-190. https://doi.org/10.1002/1098-2736(200102)38:2<159::AID-TEA1002>3.0.CO;2-J

van Zee, E. H., \& Minstrell, J. (1997). Reflective discourse: Developing shared Understandings in a Physics classroom. International Journal of Science Education, 19(2), 209-228. https://doi.org/10.1080/0950069970190206

Verplaetse, L. S. (2000). Mr. Wonderful: Portrait of a dialogic teacher. In J. K. Hall \& L. S. Verplaetse (Eds.), Second and Foreign Language Learning through Classroom Interaction (pp. 221-241). Mahwah: Lawrence Erlbaum Associates.

Vygotsky, L. (1978). Mind in Society. London: Harvard University.

Walsh, S. (2011). Exploring Classroom Discourse: Language in Action. Oxon: Routledge. https://doi.org/10.4324/9780203827826

Wells, G., \& Arauz, R. M. (2006). Dialogue in the Classroom. The Journal of the Learning Sciences, 15(3), 379-428. https://doi.org/10.1207/s15327809j1s1503_3

Wood, D. (1992). Teaching talk: How modes of teacher talk affect pupil participation. In K. Norman (Ed.), Thinking Voices: The Work of the National Oracy Project (pp. 203-214) London: Hodder and Stoughton for the National Curriculum Council.

Yip, D. Y. (2004). Questioning skills for conceptual change in science instruction. Journal of Biological Education, 38, 76-83. https://doi.org/10.1080/00219266.2004.9655905

\section{Notes}

Note 1. Episode is a collection of exchanges. An exchange consists of three moves: Initiation, Response and Evaluation or Feedback.

Note 2. Refers to student-initiated interaction in L1.

Note 3. This is a special category, where the episode was initiated as a CDE but it ended like a KTE without proper support from the students.

Note 4. In this category monologic refers to non-interactive discourse, while interactive refers to non-dialogic discourse.

Note 5. In this category monologic refers to non-interactive discourse, while interactive refers to non-dialogic discourse.

\section{Copyrights}

Copyright for this article is retained by the author, with first publication rights granted to the journal.

This is an open-access article distributed under the terms and conditions of the Creative Commons Attribution license (http://creativecommons.org/licenses/by/4.0/). 